\title{
Design and Analysis of a Concrete Placer for Optimize the Craft of Infilled Walls'S Constructional Column
}

\author{
Xiaosheng Song ${ }^{1, *}$, Shuo Wang ${ }^{2}$ and Xiaosheng Song ${ }^{3}$
}

\author{
${ }^{1}$ Hebei United University, Earthquake Engineering Research Center of Hebei Province, Tangshan, Hebei, China, \\ 063009; ${ }^{2}$ Hebei United University, Earthquake Engineering Research Center of Hebei Province, Tangshan, Hebei, \\ China, 063009; ${ }^{3}$ Hebei United University, Earthquake Engineering Research Center of Hebei Province, Tangshan, He- \\ bei, China, 063009
}

\begin{abstract}
Aiming at the construction of infill wall structural column are often used in artificial layer pouring method and top pouring back method, to improve the structure of wall column concrete pouring process, puts forward a new type of structural column concrete pouring machine. The application of this equipment, process worker can finish pouring filled wall structure column and tap filled wall structure column and unloading modulus. Reduces the labor intensity, reduces the construction cost and ensure the construction quality of frame pillar structure, realizes the structural column placement by artificial into mechanization. Introduces the design concept and the design of machinery equipment. Put forward a kind of "mixed Vibration, Lifting and Transmission" design concept. The mechanical design including a pumping device, transmission device, track lifting device, transmission device, vibration device, supporting steel template module six. Describes the structure and function of the main components of the. Describes the use of the method and the working principle of the equipment. And correlation analysis and calculation on the key parts. Presents the control principle and control calculation. Through the 3D MAX animation simulation and real structures is feasible
\end{abstract}

Keywords: Concrete pouring machine, infill wall structural column, mechanical design, the development of ideas.

\section{INTRODUCTION}

Wenchuan earthquake in 2008 and Ya' an earthquake in 2013 caused many casualties and huge property losses because large quantities of buildings were damaged by the earthquake. The problem of insufficient seismic capacity in buildings has again attracted high attention of the entire society. The research from the civil engineering structure panel of Tsinghua University, Southwest Jiaotong University and Beijing Jiaotong University showed that the brick-concrete structure buildings damaged by the Wenchuan earthquake outnumbered the frame structure buildings. Data showed that $14 \%$ of the frame structure buildings and $42 \%$ of the brickconcrete structure buildings could not be used because of the earthquake. The reason was that there were no structural columns in many old brick-concrete building during the construction, while the damage of the frame structure buildings mainly took place in the infill wall, i.e. the damage of the structural column. The experimental data from Yan Weiming etc showed that when receiving vertical force, the structural column had constraining force to the wall. Besides, according to the earthquake experience and study, the structural column can increase the shear strength of the brick-concrete wall by $10 \%$ to $30 \%$, and strengthen the ductility of the wall by over 3 times. We can see that the seismic capacity of the frame structure buildings is in general better than that of the brick-concrete buildings owing much to the layout of structural column. Therefore, to some extent, the arrangement of structural column in the wall and the improvement of the quality of structural column of the infill wall can improve the overall seismic capacity of the building. The design is a study aiming at the wall seismic capacity.

\section{PROBLEMS OF THE STRUCTURAL COLUMN}

The layout of structural column in the appropriate place of the wall can efficiently improve the seismic capacity of the wall. Wang Wenhui believes that the structural column should be placed where the stress is easy to concentrate and vertically, there should be reliable connection between the structural column and every layer of ring beam. The disqualified design or construction of the structural column will cause serious hidden safety troubles. Fig. (1) is the present complete order schematic diagram of construction of frame structure wall structural column. Usually, the steps are: step one, the forming of the main frame; step two, build the infill walls and obligate the horse-tooth-trough; step three, bind and support the frame structure structural column reinforcing cage; step four, install the frame structure structural column mould; step five, pour the frame structure structural column concrete; step six, maintain the concrete; step seven, dismantle the mould. The paper illustrates the present problems of the structural column application from problems in the construction of structural column and the shortcomings of the construction craft of structural column. 


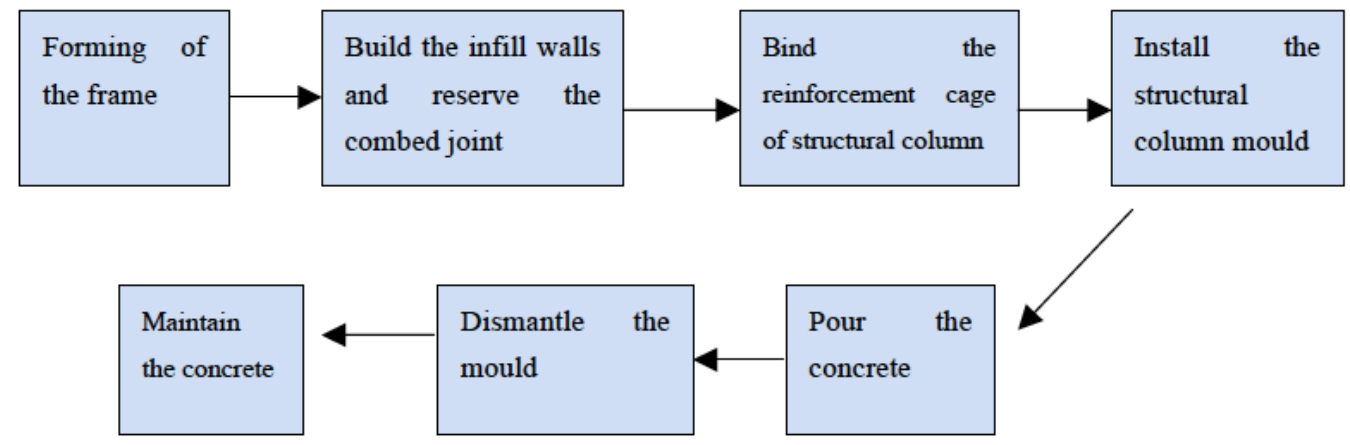

Fig. (1). Schematic diagram of the complete order of structural column construction.
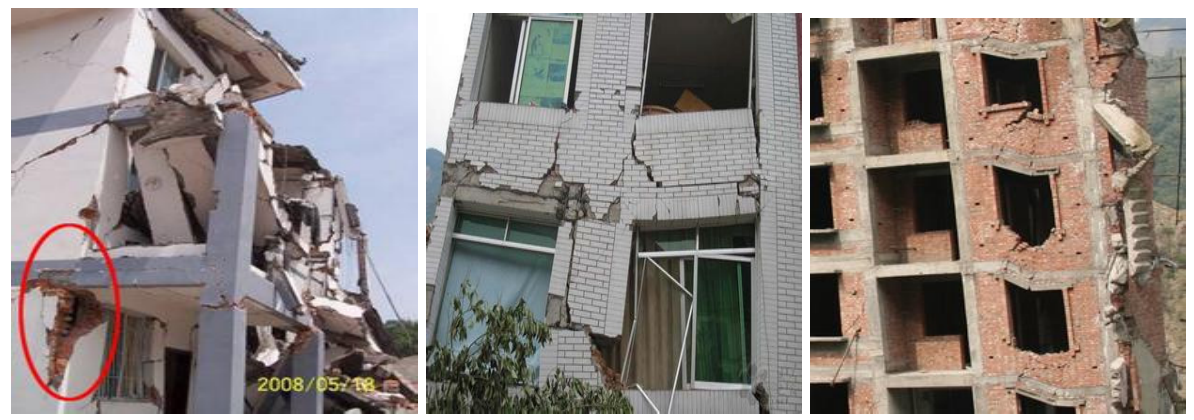

Fig. (2). The damages caused by the structural column.

\subsection{The Problems of Structural Column Construction (Affect the Quality of the Structural Column)}

The inaccurate layout of structural column like the misplacement of the upper and lower layers; the disqualified structural column bar splicing; the disqualified connection between the structural column and the wall, the weal totality; the weak concrete compaction; the weak construction quality. Defects like loose, crack, honey comb, leakage, leakage tendon and pockmark surface and soon usually happen. The contact point of column cap of the frame structure structural column and the beam is very hard to handle for artificial construction, the concrete can not be vibrated, and the impression quality can not be guaranteed.

\subsection{The Shortcomings of the Construction Craft of Structural Column}

The construction period is long, the labor investment is high and the construction cost is high.

\subsection{The Forms of Structural Column Damage}

According to the experiments of Yan Weiming and the others, there are two forms of structural column damage when receiving vertical tension. One is that the first horizontal crack appears to the column root in the elasticity-holding phase, which leads to a $45^{\circ}$ angle shear failure of the structural column and the reinforcement yielding happens; the other is that the first horizontal crack appears to the column root in the elasticity-holding phase, and because of the crack, several inclined cracks appear at the column cap and the structural column is finally shear break. Fig. (2) is the structural damages, i.e. the damages caused by the structural column.

\subsection{Solution}

Many scholars and experts have put forward some improvement plans against the above questions of the structural column, like the adoption of axis to strictly control the verticality of the structural column, to stipulate that the mixed concrete be used up in one hour and a half to guarantee its quality; to wash the mould with water before pouring the mould to make the appearance of the structural column smooth; try to pour the structural column at night to avoid the influence of the weather on the quality of the structural column. The design is aiming at the problems in the construction craft of infill wall structural column and poses a new type of structural column pouring machine.

\section{THE DEVELOPMENT OF IDEAS}

The development idea of the design is to design a machine, and through the machine we can improve the quality of the frame structure wall structural column and achieve the transformation from artificial to mechanization or halfmechanization of the construction craft in frame structure wall structural column, and hence to strengthen the seismic capacity of the wall, save the labor cost and create economic interest. The basic thought is like the following:

(1) Use the mechanical pump to carry the concrete instead of the labor force to lower the labor cost.

(2) Use the machines to build the frame structure wall structural column mould instead of the labor force to lower the labor cost.

(3) Use the machines to pour the concrete and use vibration to solve the compactness of the concrete which ca not be achieved by the labor force to improve the quality of the 


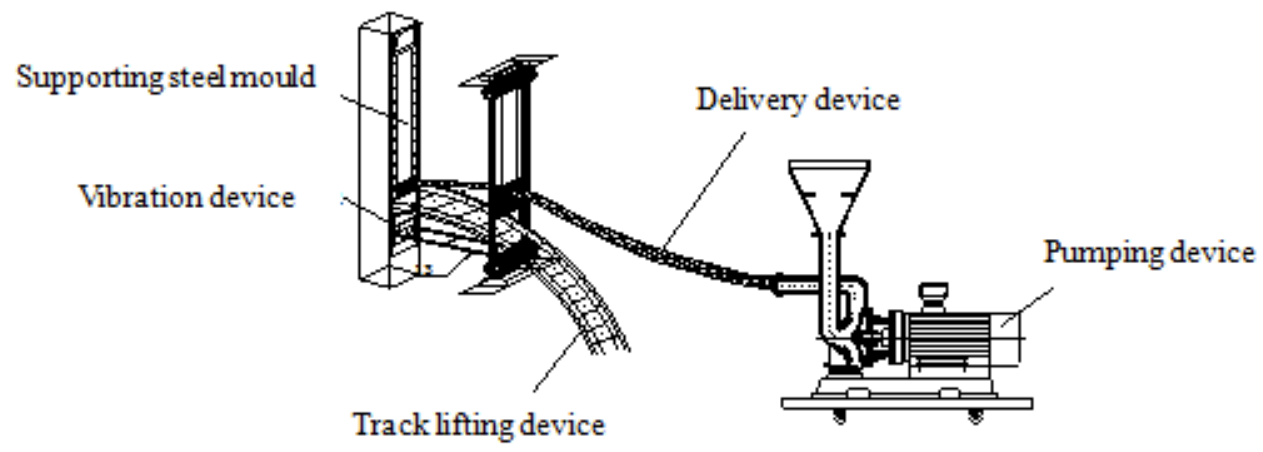

Fig. (3). Detail drawing of concrete pouring machine for infill wall structural column.

frame structure wall structural column and lower the labor cost.

\section{MECHANICAL DESIGN}

\subsection{Overall Design}

Fig. (3) shows the structure diagram of concrete pouring machine for structural column with frame structure. The design consists of such six parts as pumping device, delivery device, track lifting device, conveying device, vibration device, and supporting steel mould.

\subsection{Constitution of Mechanism}

\subsubsection{Pumping Device}

Fig. (4) shows the structural diagram of pumping device. The pumping device includes platform, material loading device and pumping motor, among which the platform consists of U-steel pedestal, pulley and flat plate and the material loading device consists of hopper and rotary vane. The pumping device is used to connect suction motor providing power source and pumping hose of conveying device. The hopper is connected to the outlet of suction motor and the suction motor is fixed on the flat plate through U-steel pedestal under which a rotary pulley is installed.

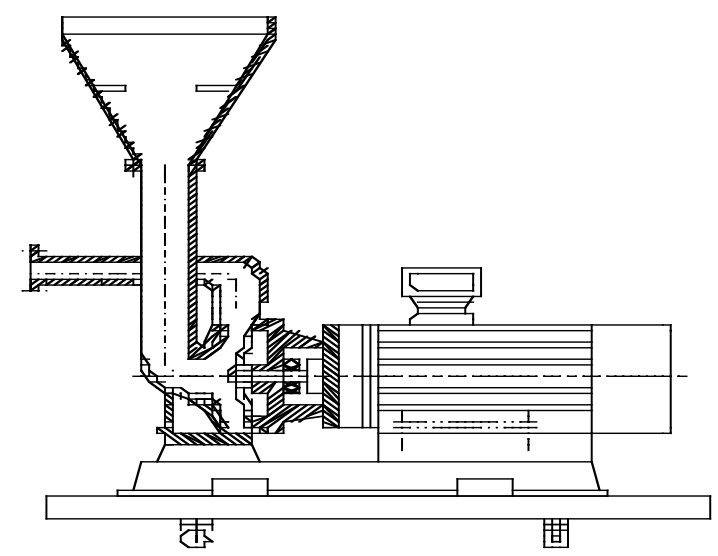

Fig. (4). Pumping device of concrete pouring device.

In order to finish the pumping of concrete and the optimization of device, selection of pumping motor is very critical. The parameters of pumping motor are shown as Table $\mathbf{1}$.
Table 1. Parameters of pumping motor.

\begin{tabular}{|c|c|}
\hline Parameter & Value \\
\hline \hline Output voltage of generator & $220 \mathrm{~V}$ \\
\hline Generator power & $220 \mathrm{kva}$ \\
\hline Travelling speed & $<0.004 \mathrm{~km} / \mathrm{h}$ \\
\hline Working efficiency & Max. pouring capacity $0.415 \mathrm{~mm}^{3} / \mathrm{h}$ \\
\hline Dimension & $1000 \times 800 \times 500(\mathrm{~mm})$ \\
\hline Rated pressure under travelling & $1.6 \mathrm{KN}$ \\
\hline Rated pressure under working & $2.5 \mathrm{KN}$ \\
\hline
\end{tabular}

Estimate of pumping motor power: V, specification of the frame structure wall structural column, is $240 * 240 * 3600 \mathrm{~mm}^{3}$, and $\gamma$, the concrete density, is $25 \mathrm{KN} / \mathrm{m}^{3}$, and $\mathrm{g}$, the acceleration of gravity, is $9.8 \mathrm{~m} / \mathrm{s}^{2}$. And then the quality of concrete needed is $\mathrm{Mt}=\gamma * \mathrm{~V} / \mathrm{g}=25 * 240 *$ $240 * 3600 * 10-6 / 9.8=529 \mathrm{~kg}$. If the friction coefficient within the pumping motor is $\mu=0.07$ and working efficiency of pumping motor is $0.415 \mathrm{~mm}^{3} / \mathrm{h}$, then

$f=$ ì $G=0.07 * 529 * 9.8=362.894$,

and 0.8 is usually taken as the working efficiency $\mu$. Assume max. Pumping efficiency

$p=(f * v / 60) / c ̧=(362.894 * 0.2 / 60) / 0.8=1.51 \mathrm{~kW}$,

in order to make the concrete being poured dense, the minimum output power of pumping motor should be controlled to be $\mathrm{P}=1.51 \mathrm{KW}$.

\subsubsection{Delivery Device}

Fig. (5) shows the structural diagram of delivery device. The delivery device means pumping hose whose one end is connected to the discharge outlet of motor and the other end is fixed to two pieces of movable steel plates. The first movable steel plate slides along with the track lifting device and the other piece of steel plate is connected to the sliding rail inside the supporting steel mould. 


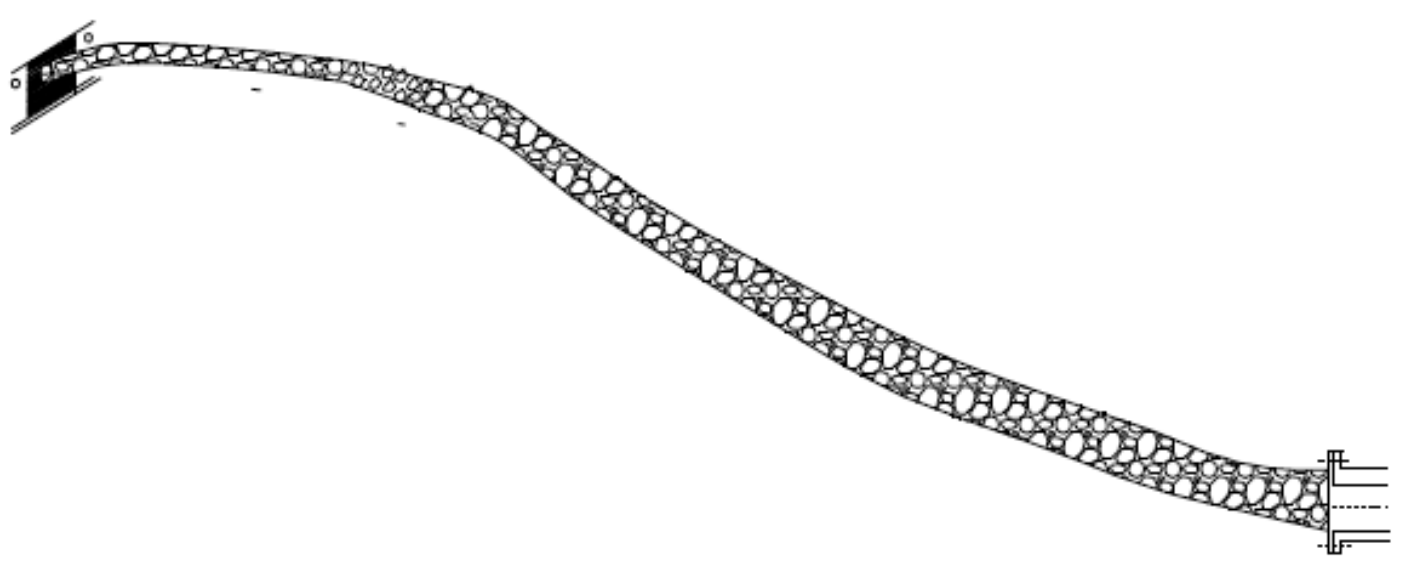

Fig. (5). Schematic diagram of delivery device.

In order to make sure concrete delivered to the track lifting device, selection of the specification and material of delivery device is of great importance. Fire hose is planned as the pumping hose.

(1) Selection of the specification of pumping hose: the pumping hose can be classified, according to the inner diameter, as $\varphi 2^{\prime} \varphi 40^{\prime} \varphi 50^{\prime} \varphi 65^{\prime} \varphi 80^{\prime} \varphi 90^{\prime} \varphi 100^{\prime} \varphi 150$. The inner diameter of the pumping hose should be in consistence with the specification of the discharge outlet of pumping motor. The condition pumping hose has to satisfy is that the design can still work properly even when the track lifting device rises to top of structural column. But the pumping hose should not be too long. If the pumping hose is too long, more powerful pumping motor will be needed to pump concrete. But the adoption of more powerful pumping motor will make the pumping rate too quick when pouring concrete on the bottom of structural column, and then the overall quality of the structural column will be affected.

(2) Selection of the material of pumping hose: the friction coefficient of concrete is high. The pressure will be exerted on the hose wall when concrete passes through the pumping hose. So the pumping hose should select the material with a certain degree of wear resistance and rigidity. Polyurethane is possessed of such chemical property as resistance to various kinds of acids and bases and resistance to the corrosion of organic solvent and of the property of wear resistance, temperature resistance and sealing. The advanced fire hose made of polyurethane can meet the above-mentioned requirements.

\subsubsection{Track lifting Device}

Fig. (6) shows the structure of track lifting. The track lifting device consists of pedestal, motor, reel, pulley, support frame, linkage, vertical pole, fixed link structure, and steel plate. The fixed link structure contacts with the bottom of roof boarding and is fixed on the floor by sucking dis. The pulley lies inside the rail and is connected to linkage and the first piece of movable steel plate. The support frame is composed of rail and vertical pole, and the device has two reels, the upper reel and the lower reel. The lower reel is fixed to the sliding motor to provide power for lifting the track. Intertwined with transmission flexible shaft, the upper reel is foxed to the sliding motor. By connecting with movable plate, the transmission flexible shaft can provide more power. The support frame is fixed to the pedestal and fixed link structure. One end of the two vertical poles is fixed to the movable steel plate and the other end of the two poles is fixed to the two ends of the linkage. The first piece of movable steel plate, two vertical poles, linkage and the conveyor belt constitute an integral whole which is powered by sliding motor and lifting motor to realize its sliding up and down.

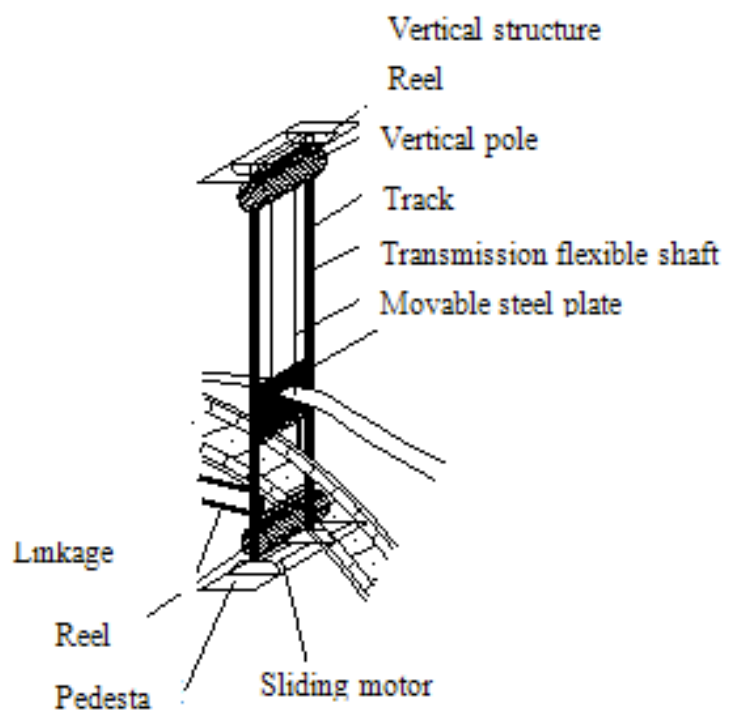

Fig. (6). Schematic diagram of track lifting device.

In order to make sure that the movable plate can drive pumping hose to realize track lifting and to realize the optimization of the device, selection of the material of movable steel plate and power of lifting motor is of great importance.

(1) Selection of the material of movable steel plate: The movable steel plate must bear the pressure exerted by concrete in the pumping hose, and therefore the movable steel plate with a certain degree of rigidity should be selected. The frequently used steel includes carbon steel and stainless steel. The carbon steel is possessed of relatively large strength, rigidity and wear-resistance. The 
stainless steel is possessed of good corrosion resistance and oxidation resistance and it's not easy for it get corrosive or rusty. After comparing the two kinds of steel, it is found that although carbon steel is more liable to get corrosive than stainless steel, carbon steel is a lot cheaper than stainless steel. The material of stainless steel should be selected according to the actual conditions.

(2) Calculation of the power of lifting motor: because lifting motor adopts vertical shaft style hoister, the calculation of lifting motor should adopt dynamic coefficient method.

$$
p=9.81 K Q H \tilde{n} / 1000 \mathrm{Tç}
$$

among the expression:

P----power of motor shaft, $\mathrm{KW}$;

$\mathrm{K}$---damping coefficient, usually take 1.2 ;

Q----effective lifting quality, $\mathrm{kg}$;

H----lifting height, $\mathrm{m}$;

T----pure operation time excluding shutoff time, s;

$\eta$----transmission efficiency of reducer, and 1 is taken under the condition of direct-connected transmission;

P---- dynamic coefficient, and 1.3 1.4 is taken under the condition of lifting with no turn-over;

The pure operation time, $\mathrm{T}$, can be calculated through the following expression:

$$
T=3600 Q / A h-\mathrm{è}
$$
$\mathrm{kg}$;

among the expression: Ah----lifting capacity per hour,

$\Theta$----shutoff time, s;

Q----effective lifting quality, $\mathrm{kg}$.

\subsubsection{Conveying Device}

Fig. (7) shows the schematic diagram of conveying device. The conveying device consists of conveyor belt and specially made steel plate. There are two keyholes on the right side and left side of the specially made steel plate adjacent to structural column. The projected snap joints whose diameters are slightly greater than the keyhole of the specially made steel plate are set on the two sides of the sliding rail of supporting steel mould respectively and they are used for fixing the sliding rail and specially made steel plate.

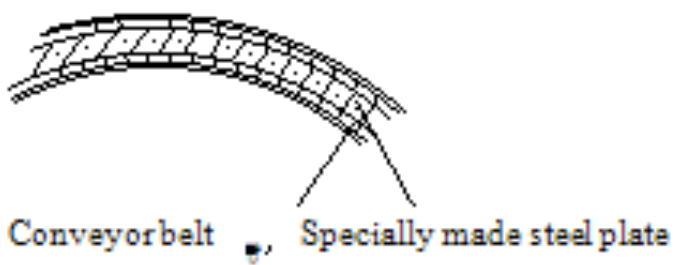

Fig. (7). Schematic diagram of conveying device.
The conveying device is used to connect supporting steel mould and under the combined action, the concrete is sealed. In order to finish the process, selection of the material of conveyor belt and the specially made steel mould is of great importance.

In terms of the conveyor belt, the light conveyor belt made of new material can be selected. The new material type conveyor belt is light and thin and is characterized by good dimensional stability, static-free, and corrosion-resistance. The average thickness of base belt of new material light type conveyor belt is $0.6-6 \mathrm{~mm}$, and the product precision reaches $\pm 0.02 \mathrm{~mm}$. The max. tensile modulus can reach $100 \mathrm{~N} / \mathrm{mm}$ and the proportion is $3.3 \mathrm{~kg} / \mathrm{m}^{2}$. The new material light type conveyor belt conforms to the requirements of environmental protection and can save the power consumption [1-5] of conveyor belt in the process of conveying. The selection of the material for specially made steel mould should be the same as the selection of material for the movable steel plate in the track lifting device mentioned above.

\subsubsection{Vibrating Device}

Vibration motor is fixed on the linkage. Connected to the conveyor belt through special connection type, vibration motor is tightly connected with the supporting steel mould. Different vibrational frequency is transmitted by the vibration motor transmits to the specially made steel plate on conveyor belt, and the specially made steel plates are constantly overlain on the supporting steel mould. In order to make sure the concrete reaches the dense state through the vibration of vibration motor, selection of vibration motor is of great importance.

Selection of parameters of vibration motor provided by some company is shown in Tables $\mathbf{2}$ and $\mathbf{3}$, different vibration motors are selected according to different vibration needs.

\subsubsection{Supporting Steel Mould Plate}

Fig. (8) shows the schematic diagram of supporting steel mould plate. The supporting steel mould plate is composed of steel mould plate, sliding rail, and sliding rod. One end of each of the two sliding rods is connected, through electric welding, with the linkage, conveyor belt, movable steel plate to constitute an integral whole. By connecting with the vibration motor, the other end of each of the two sliding rods worked with sliding rail to drive the vibration motor to work and slide up and down. On the top of the steel mould plate, there is a tilted support plate and support rib plate which are fixed to the steel mould plate through bolts.
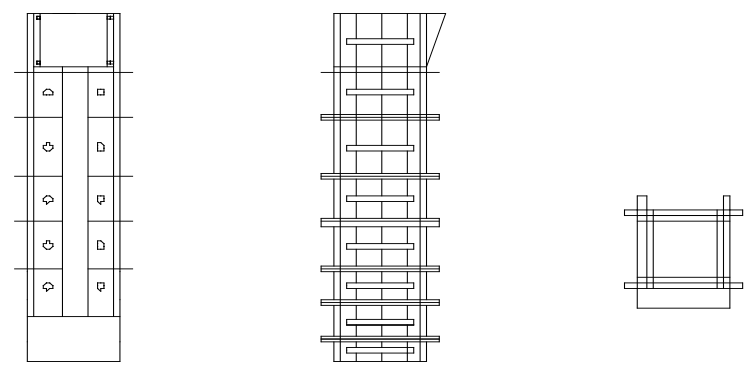

Fig. (8). Schematic diagram of supporting steel mould plate. 
Table 2. Overall and installation dimension.

\begin{tabular}{|c|c|c|c|c|c|c|c|c|c|c|c|c|}
\hline $\begin{array}{c}\text { Installation dimension } \\
\text { Installation) }\end{array}$ & \multicolumn{9}{|c|}{$\begin{array}{c}\text { Overall dimension } \\
\text { (Dimensions) }\end{array}$} \\
\hline \hline $\mathrm{I} / \mathrm{I} 1$ & $\mathrm{~L} / \mathrm{L} 1$ & $\mathrm{~A}$ & $\mathrm{~B}$ & $\mathrm{C}$ & $\mathrm{D}$ & $\mathrm{E}$ & $\mathrm{G}$ & $\mathrm{H}$ & $\mathrm{M}$ & $\mathrm{N}$ & $\mathrm{Q}$ \\
\hline 30 & 91 & 150 & 110 & 70 & 60 & 32 & 30 & $\oint 7$ & 11 & 58 & 18 \\
\hline 30 & 91 & 168 & 110 & 80 & 66 & 37 & 33 & $\oint 9$ & 10 & 68 & 14 \\
\hline
\end{tabular}

Table 3. Main parameters of motor performance.

\begin{tabular}{|c|c|c|c|c|c|c|}
\hline \multirow[t]{2}{*}{ (Type) } & \multirow{2}{*}{$\begin{array}{c}\text { (Voltage) } \\
\text { V }\end{array}$} & \multirow{2}{*}{$\begin{array}{c}\text { (PHase) } \\
\text { PH }\end{array}$} & \multirow{2}{*}{$\begin{array}{c}\text { (Power) } \\
\text { W }\end{array}$} & \multirow{2}{*}{$\begin{array}{c}\text { (Current) } \\
\text { A }\end{array}$} & $\begin{array}{c}\text { (Frequency RPM) } \\
\text { RPM }\end{array}$ & \multirow{2}{*}{$\begin{array}{c}\text { (Force) } \\
\text { KN }\end{array}$} \\
\hline & & & & & $50 \mathrm{HZ} / 60 \mathrm{HZ}$ & \\
\hline $\mathrm{Xc}-\mathrm{L} 15 / 2(1)$ & $220 \mathrm{~V} / 110 \mathrm{~V}$ & $1 \mathrm{PH}$ & 15 & $0.10 \mathrm{~A} / 0.21 \mathrm{~A}$ & $3000 / 3600$ & 20 \\
\hline $\mathrm{Xc}-\mathrm{L} 20 / 2(1)$ & $220 \mathrm{~V} / 110 \mathrm{~V}$ & $1 \mathrm{PH}$ & 20 & $0.11 \mathrm{~A} / 0.22 \mathrm{~A}$ & $3000 / 3600$ & 25 \\
\hline Xc-L35/2(1) & $220 \mathrm{~V} / 110 \mathrm{~V}$ & $1 \mathrm{PH}$ & 35 & $0.14 \mathrm{~A} / 0.25 \mathrm{~A}$ & $3000 / 3600$ & 35 \\
\hline $\mathrm{Xc}-\mathrm{L} 40 / 2(1)$ & $220 \mathrm{~V} / 110 \mathrm{~V}$ & $1 \mathrm{PH}$ & 40 & $0.16 \mathrm{~A} / 0.27 \mathrm{~A}$ & $3000 / 3600$ & 40 \\
\hline Xc-L45/2(1) & $220 \mathrm{~V} / 110 \mathrm{~V}$ & $1 \mathrm{PH}$ & 45 & $0.23 \mathrm{~A} / 0.45 \mathrm{~A}$ & $3000 / 3600$ & 45 \\
\hline $\mathrm{Xc}-\mathrm{L} 50 / 2(1)$ & $220 \mathrm{~V} / 110 \mathrm{~V}$ & $1 \mathrm{PH}$ & 50 & $0.24 \mathrm{~A} / 0.46 \mathrm{~A}$ & $3000 / 3600$ & 50 \\
\hline Xc-L65/2(1) & $220 \mathrm{~V} / 110 \mathrm{~V}$ & $1 \mathrm{PH}$ & 65 & $0.31 \mathrm{~A} / 0.63 \mathrm{~A}$ & $3000 / 3600$ & 75 \\
\hline Xc-L70/2(1) & $220 \mathrm{~V} / 110 \mathrm{~V}$ & $1 \mathrm{PH}$ & 70 & $0.32 \mathrm{~A} / 0.64 \mathrm{~A}$ & $3000 / 3600$ & 80 \\
\hline $\mathrm{Xc}-\mathrm{L} 75 / 2(1)$ & $220 \mathrm{~V} / 110 \mathrm{~V}$ & $1 \mathrm{PH}$ & 75 & $0.35 \mathrm{~A} / 0.69 \mathrm{~A}$ & $3000 / 3600$ & 90 \\
\hline
\end{tabular}

So that the concrete can be sealed and the vibration of concrete can be finished under the combined action of supporting steel mould plate and conveying system. Selection of the supporting steel mould plate is the same as the abovementioned selection of movable plate inside the track lifting device.

\section{SPECIFICATION OF THE EQUIPMENT OPERA- TION}

\subsection{Construction Craft}

The application method and working principle of the design are elaborated.

\subsubsection{Operation Process of Equipment}

When the concrete pouring machine for the frame structure wall structural column to pour concrete for structural column, the equipment should be installed firstly and be checked to make sure all parts are in normal condition before it is in operation. Pour the mixed concrete into the material loading device and when the concrete is delivered to the supporting steel mould plate through delivery device, activate track lifting device, conveying device and vibration device to achieve the effect of compacting the concrete by vibration while filling the structural column with concrete. The shape of the frame structure wall structural column has been formed and concrete-pouring needs to be stopped when the concrete spills from the column top of frame structure wall structural column. Disconnect the concrete pouring machine for structural column of frame structure from the supporting steel mould plate and clear the site. Dismantle the tilted support template and remove redundancy when the structural column of frame structure achieves a certain degree of strength.

\subsubsection{Working Principle of Equipment}

Pour the mixed concrete into the hopper and then the concrete will be conveyed to the supporting steel mould plate through the helical blade and pumping motor. The concrete will be pumped into frame structure wall structural column by the track lifting device's driving the integral structure composed of linkage, vibration motor, movable steel plate, conveying device to move up and down. Conveyed to the supporting steel mould plate, the specially made steel plate will cooperate well with vibration motor to make sure the specially made steel plate and steel mould plate are 
tightly connected, thus improving the overall rigidity of the mould plate and effectively prevent such unfavorable conditions as concrete overflow and slurry explosion in the process of pouring concrete. When concrete is poured to the lower part of the tilted support plate of structural column for frame structure, the integral part composed of linkage, vibration motor, movable steel plate and conveying device will work continuously. The shape of the frame structure wall structural column has been formed and concrete-pouring needs to be stopped when the concrete spills from the column top of frame structure wall structural column, and then some time will be needed for the structural column to achieve a certain degree of rigidity. After that, the concrete pouring process for the frame structure wall structural column is completed.

\subsubsection{Optimizing Structure}

Some helical blades can be installed on the inner wall of material-loading device; The swivel wheel can be installed beneath the flat plate of pumping device so that it will be convenient for the concrete pouring machine to move to another structural column of frame structure to pour concrete when the concrete-pouring for one structural column of frame structure is finished; change the lifting motor to hydraulic motor so that the slow and orderly power source can be provided for track lifting device; The support frame can be set as the vertically contractile track and vertical pole to facilitate the construction of structural column of frame structure with different floor height.

\subsection{Description of Installation and Dismantlement}

The chapter will elaborate the design's installation before its use and its dismantlement after its use.

\subsubsection{Description of the Installation}

The concrete pouring machine for the structural column of frame structure, pumping device, track lifting device and supporting steel mould plate should be manufactured according to the design dimension and the model of such related parts as suction motor, lifting motor, and vibration motor should also be purchased on the basis of design dimension; The suction motor should be installed well with its corresponding feed outlet and discharge outlet before it is fixed on the flat plate; All parts of the manufactured track lifting device should be assembled according to the requirements, and after the assembly, the pumping device should be connected with track lifting device by the pumping hose of the delivery device; carefully check all joint parts, and then prepare the overlap joint between concrete pouring machine of structural column of frame structure and supporting steel mould plate; after the overlap joint, the concrete pouring machine for frame structure wall structural column starts working.

\subsubsection{Dismantlement Description of Concrete Pouring Machine for the Structural Column of Frame Structure}

Dismantle the concrete pouring machine for structural column of frame structure from the supporting steel mould plate; after dismantling the pumping hose of the concrete pouring machine for structural column of frame structure, dismantle the track lifting device; use tower crane to lift all parts to the ground and then the dismantlement is completed.

\section{CONCLUSION}

It is found, through the design of the concrete pouring machine for infill structural column, theoretical analysis and finite element analysis, that the design has great advantages in comparison with the current pouring method of structural column. The design saves manpower and improves working efficiency by replacing manual operation with machinery; the design can constantly vibrate concrete while pouring concrete by using vibrator, making the concrete achieve dense state. The use of supporting steel mould plate avoids the occurrence of concrete overflow and slurry explosion, improving the quality of structural column. The man-made quality defects are avoided as much as possible, promoting the development of construction mechanization.

\section{CONFLICT OF INTEREST}

The authors confirm that this article content has no conflict of interest.

\section{ACKNOWLEDGEMENTS}

Declared none.

\section{REFERENCES}

[1] "Civil and Structural Groups of Tsinghua University, Xinan Jiaotong University and Beijing Jiaotong University, Journal of Building Structures, vol. 29, no. 4, pp. 2-6, 2008.

[2] W. Yan, H. Zhou, X. Zhou, Q. Sun, "Experimental study on seismic behavior of small concrete hollow block walls restricted by constructional column," Journal of Building Structures, vol. 26, no. 4, pp. 66-67, 2005.

[3] W. Wang, "Construction Quality Control of Constructional Column in Multistoried Buildings with Brick-concrete Composite Structure," Construction Technology, vol. 40, pp. 425-426, 2011.

[4] Y. Li, "Common Quality Defects and Prevention Measures in Structural Column Construction," Construction Technology, vol. 37, pp. 398-399, 2008.

[5] Q. Xu, "Current State and Development Trends of New-materialsbased Light Conveyor Belts in China," China Plastics, vol. 24, no. 11, pp. 7, 2010.

\footnotetext{
Received: February 03, 2015

Revised: April 03, 2015

Accepted: May 25, 2015

(C) Song et al.; Licensee Bentham Open.

This is an open access article licensed under the terms of the (https://creativecommons.org/licenses/by/4.0/legalcode), which permits unrestricted, noncommercial use, distribution and reproduction in any medium, provided the work is properly cited.
} 